Ronald Hitzler

Sinnwelten 
Beiträge zur sozialwissenschaftlichen Forschung

Band 110 


\section{Ronald Hitzler}

Sinnwelten

Ein Beitrag zum Verstehen von Kultur 
CIP-Titelaufnahme der Deutschen Bibliothek

Hitzler, Ronald;

Sinnwelten: e. Beitr. zum Verstehen von

Kult ur/Ronald Hitzler. - Opladen:

Westdt. Verl, 1988

(Beicräge zur sozialwissenschaftlichen

Forschung; Bd. I 10)

ISBN 978-3-531-12030-0

ISBN 978-3-322-88882-2 (eBook)

DOI 10.1007/978-3-322-88882-2

NE: GT

Der Westdeutsehe Verlag ist cin Unternehmen der Verlagsgruppe Bertelsmann.

Alle Rechte vorbehalten

(c) Springer lactumedien Wiesbaden 1988

I Jsprünglich erschienen bei Westdeutscher Verlag GmbH, Opladen in 1988

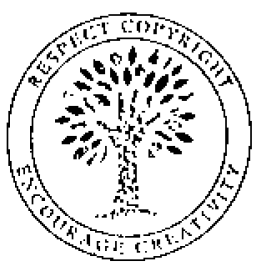

Das Werk einschließlich aller seiner Teile ist urheberrechtlich geschützt. Jede Verwertung au(kerhalb det engen Grenzen des Urheberrechtsgeserzes ist ohne Zustimnung des Verlags unculassig und strafbar. Das gilt insbesondere für Vorielfätigungen, Ubersetzungen, Mikrovertilmungen und die Einspticherung und Verarbeitung in elektronischen Systemen.

Unschlaggestaltung: Hanswerner Klein, Opladen 
Für Anne und Anni

"The word 'real' itself is, in short, a fringe."

(William James)

Diese Arbeit wurde von der Fakultät Sozial und Wirtschaftswissenschaften der Universität Bamberg unter dem Titel 'Kleine Konstruktionen. Ein Beitrag zum Verstehen von Kultur' als Dissertation angenommen. Der Verfasser bedankt sich bei seinen Betreuern, der Herrn Professoren Dr. Peter Gross und Dr. Ulrich Beck. 
Statt eines Vorworts:

Der Theorist

Ein Buchhalter der Unvernunft; war's das, so fragte er sich, was aus dem wurde, was aus ihm hatte werden sollen? - Schließlich hatte man's ihm oft genug gesagt: alles, was er sagen wolle, solle er klar sagen, hatte man ihm gesagt: wohl wohlwollend wollend, daß er doch sage und schreibe ...

... aber alles, was er zu sagen hatte, hing, halbgereimt, in diesen bürotischen Kästen, stapelte sich ellenhoch übers möblierte Gelände und reihte sich schubrig von Abe bis Zima. Nichts, und wirklich: nichts war klar in dieser Wüste aus Papier, die sich in Dünen, Wällen, Halden, in Vorgebirgen rings, und wirklich: rings um ihn erstreckte. Zum Sagen aber war's ihm allemal, nebst diesen Schlenkern in erhoffte Neben-Sächlichkeiten. Zum Schreiben übrigens auch, notierte er (wieder einmal) nicht, gewahrend, daß er eifriges Notieren stets verabsäumt hatte, seit er anschrieb (wogegen ließ er sich nur ungern fragen, auch von sich selbst) und anschreiben ließ (mithin auf der Soll-Seite lebend): seine Zukunft kreditierend, die er noch keinesfalls hinter sich glaubte.

In lichten Augenblicken zwar erkannte er, erschreckend, sich in jenes Gundlings Spuren stapfend, doch allzumeist erwählte er sich eher pantheonisch. Und drum: Gut denn: buchhalterisch galt's hier zu wirken. Poeten sperrt Euch selber aus! (Des Elfenbeingetürmes Wall ist eine dicke Haut und ohne Hintertür: Der Zopf, den keiner schneiden mag, wirkt gar zu wirklich weil, oh nein: obwohl er pendelt: Rapunzel fordert strengeren Diskurs.) Tatsachen, mein Freund, Tat-Sachen. Bloß nicht, entfuhr's ihm, wie einem Solches eben zu entfahren pflegt, bloß nicht, nicht diese Form(an)alitäten: Passierscheine sind's, der Sprachlosen und Phantasieverschreckten.

Ein Borchertsches Frösteln befiel ihn, just an dieser Stelle; und er hätte sich gerne den klammen Mantel wärmend um die kalten Schultern (die's doch zu zeigen galt) gezogen, wär er nicht, ja, wär er nicht völlig nakkend, zu frühherbstheit'rer Morgenstund, in lichter Stube gesessen (zentralbeheizt). Wie schwer war's doch, selbst nackt, der nackten Existenz auf die Bocksprünge ihrer Eigentlichkeit zu kommen. 
Inhalt

I. Vor-Verständigung 5

Über die Konstruktion der Perspektive und ihre Konsequenzen

II. Übungen zur Hermeneutik der sozialen Existenz 11

1. Rationales Verstehen (Schütz) 11

Sinn-Rekonstruktion als epistemologisches, alltägliches und sozialwissenschaftliches Problem - Strukturen der Lebenswelt - Zum Verhältnis von Phänomenologie und Soziologie

2. Kontemplatives Verstehen (Wolff)

Empathie als Hingebung-und-Begriff - Kritik der Kritik von Agnes Heller - Zum Problem ethischer Postulate

3. Dialektisches Verstehen (Sartre)

Totalisierung - Bewußtsein in Situation - Das Erscheinen des Anderen - Serie und Gruppe als Movens sozialen Wandels - Zum Verhältnis von Soziologie und Existentialismus

4. Existenzialer Skeptizismus: Eine programmatische Perspektive

Werturteilsfreiheit und 'Sorge' - Der GegenStand - Zur Notwendigkeit soziologischer (Selbst-)Reflexivität

III. Annäherungen an den Kulturmenschen

1. Wissen aus zweiter Hand

Soziologisches Denken - Alltagsverstand - Zur Dialektik kollektiven Wissens

2. Unterwegs im Alltag

Die Konstruktion von Kultur als einer sozialen Tatsache - Privatheit und Öffentlichkeit - Die dramaturgische Relevanz appräsentativer Medien 
3. Auf Umwegen und Abwegen

Dimensionen der Lachkultur - Spielen und Spiele - Exkurs in den Anarchismus - Religiosität als Pforte der Phantasie

$\begin{array}{ll}\text { IV. Streifzüge durchs Leben } & 109\end{array}$

1. Fremde Menschen 109

Archaische Welterfahrung - Exkurs in den Schamanismus - Traditionale Ordnung - Exkurs in die Narretei

2. Moderne Zeiten

Teilzeit-Perspektiven - Exkurs ins Deutsche Lebensstil und Sinn-Bastelei - Exkurs in die Collage (am Beispiel des Werks von Frank Zappa) - Politische Konsequenzen - Arbeiten unter den Bedingungen des linearen Zeitbewußtseins

3. Fatale Aussichten?

Diffusion von Erwerbsarbeit und Freizeit - Neue Antagonismen und Risiken - Zu den Chancen einer proteischen Praxis

V. Nach-Denken

Über das Schillern des kulturellen Lebens

Anmerkungen 